\title{
Ultrasound diagnosis of lung herniation: The push-out sign
}

\author{
Luca Iaboli, ${ }^{1}$ Luca Baldini, ${ }^{2}$ Roberto Galassini, ${ }^{1}$ Roberto Copetti ${ }^{3}$ \\ ${ }^{1}$ General Practice, Azienda Unità Sanitaria Locale di Modena; ${ }^{2}$ Radiology Department, Azienda \\ Ospedaliero-Universitaria di Modena, Ospedale Civile di Baggiovara; ${ }^{3}$ Emergency Department, Azienda \\ Ospedaliero-Universitaria Ospedali Riuniti, Trieste, Italy
}

\begin{abstract}
Lung ultrasound is an expanding field and is becoming a standard of care. Its various bedside applications have modified many diagnostic paths from the newborn to the geriatric patient. In this case report, we describe and show a new sign of the lung ultrasound semeiotics, the push-out sign.
\end{abstract}

\section{Case Report}

A 55-year-old woman came up to our general practice office complaining about a cough which had lasted for two weeks. She was in good general condition and she had no fever or other major symptoms.

Physical examination revealed a deformation of the thorax: a well-circumscribed oval shaped bulge was evident during coughing in the eighth intercostal space of the left mid-axillary region. The chest wall bulge was soft and tender at palpation and wasn't apparent during normal respiration but it was easy to detect during cough or Valsalva maneuver (Supplementary file A).

The patient did not report any recent traumatic event, but had underwent a hysterectomy 7 years earlier for a low-grade uterine mixoid leiomyosarcoma.

\footnotetext{
Correspondence: Luca Iaboli, General Practice, Azienda Unità Sanitaria Locale di Modena, Via S. Giovanni del Cantone 23, 41121 Modena, Italy.

Tel.: +39.053629562.

E-mail: liaboli@hotmail.com

Key words: Lung ultrasound; Lung herniation; Push-out sign.

Contributions: LI formulated the ultrasound diagnosis and wrote the initial draft. All authors searched the literature, made critical revisions, and approved the final version.

Conflict of interest: the authors declare no potential conflict of interest.

Funding: none.

Received for publication: 6 September 2018 .

Revision received: 9 October 2018.

Accepted for publication: 30 October 2018.

This work is licensed under a Creative Commons Attribution 4.0 License (by-nc 4.0).

(C) Copyright L. Iaboli et al., 2018

Licensee PAGEPress, Italy

Emergency Care Journal 2018; 14:7808

doi:10.4081/ecj.2018.7808
}

One year before our visit, a follow up positron emission tomography/computed tomography (CT) showed new focal hypercaptation of suspected neoplastic nature in the posterior segment of the left lower pulmonary lobe. A mini-thoracotomy was performed and the pulmonary parenchyma resulted free from neoplastic infiltration.

A chest ultrasound just over the bulge showed the lung and pleura moving externally with expiration and internally with inspiration (Figure 1). We also registered ultrasound images of the lung herniation during a Valsalva maneuver (Supplementary file B).

We sent the patient for a chest X-Ray by which it wasn't possible to identify the hernia. Because of the relatively young age of the patient and the amount of radiation absorbed during the previous year, we decided not to proceed with a CT $\operatorname{scan}^{1}$ to confirm the already evident diagnosis.

\section{Discussion}

Lung herniation is defined as a protrusion of the lung parenchyma with pleural membranes through a defect of the thoracic wall. The first published description dates back to 1845 when Morel-Lavallée collected 32 cases. $^{2}$ Lung herniation may be classified as congenital, traumatic or post-thoracotomy. Hernia after cardio-thoracic procedures is an uncommon entity. ${ }^{3}$ A single institution retrospective review of patients submitted to thoracic surgery identified it in only 16 patients over 10 years. ${ }^{4}$

In the case we describe, the cough effort, increasing intrathoracic pressure in a zone of greater laxity, determined the emergence of the hernia well over a year after surgery. ${ }^{5}$

Controversy still exists concerning the role of surgical repair and at the moment our patient is asymptomatic and the management is conservative.

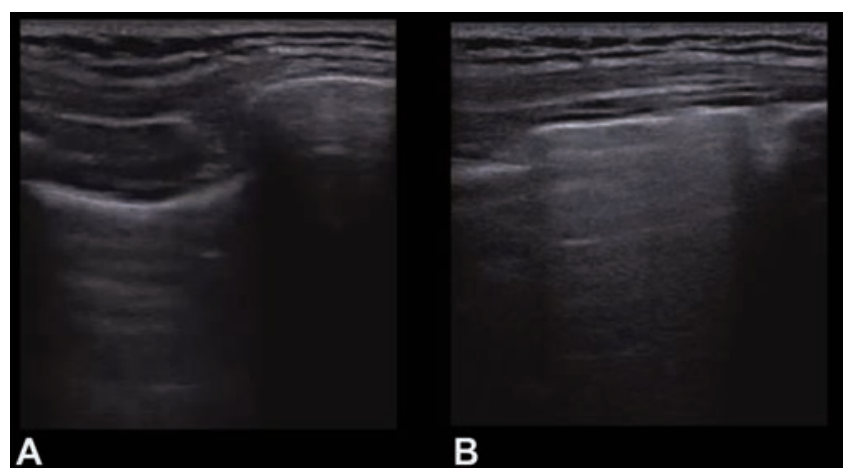

Figure 1. (A) Normal ultrasound image of the lung: pleura can be seen in between and under the ribs; (B) the push-out sign: pleura is now visualized out of the ribs. 


\section{Conclusions}

The diagnosis of lung herniation is usually possible after an accurate history and a clinical examination showing the typical bulge which changes with respiration or with the cough. A confirmation may come from chest sonography. In this case report we described a new lung ultrasound sign which is pathognomonic for lung herniation and which we named the thoracic push-out sign.

\section{References}

1. Detorakis EE, Androulidakis E. Intercostal lung herniation The role of imaging. Radiol Case 2014;8:16-24.

2. Morel-Lavallée A. Hernies du poumon. Bull Soc Chir Paris 1845-1847;1:75-195.

3. Afzal MR, Wilson JH. Images in clinical medicine. Lung herniation after cardiac surgery. N Engl J Med 2013;368:e35.

4. Athanassiadi K, Bagaev E, Simon A, Haverich A. Lung herniation: a rare complication in minimally invasive cardiothoracic surgery. Eur J Cardio-thoracic Surg 2008;33:774-6.

5. Asenjo M, Angelina M. Images in clinical medicine. Lung herniation with coughing. N Engl J Med 2015;372:464. 